\title{
Early predictors of continuous positive airway pressure failure in preterm neonates
}

\author{
Venkatakrishna Kakkilaya $\mathbb{I}^{1}$ - Sheron Wagner ${ }^{3} \cdot$ Kate Louise M. Mangona $^{2} \cdot$ L. Steven Brown ${ }^{3} \cdot$ Ihab Jubran $^{1}$. \\ Henry He ${ }^{1} \cdot$ Rashmin C. Savani ${ }^{1} \cdot$ Vishal S. Kapadia ${ }^{1}$
}

Received: 8 November 2018 / Revised: 4 April 2019 / Accepted: 8 April 2019 / Published online: 14 May 2019

(c) Springer Nature America, Inc. 2019

\begin{abstract}
Objective To develop a prediction model to identify infants admitted on continuous positive airway pressure (CPAP) requiring intubation within seventy-two hours of life (HOL).

Study design Infants born $\leq 29$ weeks' gestational age between 2013 and April 2018 were randomly assigned to either a modeling cohort (MC) or a validation cohort (VC) in a 2:1 ratio. Variables available within two HOL were compared between the CPAP failure group (CFG) and the CPAP success group (CSG).

Results Of the 189 infants in the MC, 50\% failed CPAP. Compared to CSG, infants in the CFG had lower antenatal steroid exposure, birth weight, higher radiographic severe respiratory distress syndrome (RDS) and fraction of inspired oxygen $\left(\mathrm{FiO}_{2}\right)$. A forward stepwise logistic regression modeling in both $\mathrm{MC}$ and $\mathrm{VC}$ showed that $\mathrm{FiO}_{2}>0.3$ and radiographic severe RDS predicted CPAP failure.

Conclusion $\mathrm{FiO}_{2}>0.3$ within two $\mathrm{HOL}$ and radiographic severe RDS predicts CPAP failure in preterm infants.
\end{abstract}

\section{Introduction}

The risks of mechanical ventilation (MV) to premature lungs is well known. Even a brief exposure to large volume breaths can initiate an inflammatory cascade leading to bronchopulmonary dysplasia (BPD) [1-3]. Avoiding intubation in the delivery room (DR) and stabilization with continuous positive airway pressure (CPAP) improves outcomes [4-6]. In recent years, preterm infants are increasingly being admitted to the neonatal intensive care unit (NICU) on CPAP [7, 8]. However, 40-65\% of these infants require intubation and mechanical ventilation during the first three days of life [8-10]. Importantly, infants failing

Venkatakrishna Kakkilaya

Venkat.Kakkilaya@UTsouthwestern.edu

1 Division of Neonatal-Perinatal Medicine, Department of Pediatrics, University of Texas Southwestern Medical Center, Dallas, TX, USA

2 Division of Pediatric Radiology, Department of Radiology, University of Texas Southwestern Medical Center, Dallas, TX, USA

3 Parkland Health and Hospital System, Dallas, TX, USA
CPAP have worse outcomes compared to those who successfully remain on CPAP [11-13]. Identifying infants at risk for CPAP failure could help target early interventions to avoid intubation and MV.

Previous studies that evaluated both antenatal and immediate postnatal factors to predict CPAP failure have provided varying results [11, 13-15]. A single center retrospective study by Ammari et al. reported that birth weight $\leq 750 \mathrm{~g}$, GA $<26$ weeks, alveolar-arterial oxygen gradient (A-a $\left.\mathrm{DO}_{2}\right)>180 \mathrm{mmHg}$, and severe respiratory distress syndrome (RDS) on the initial chest radiograph were predictive of CPAP failure among infants born $\leq 1250 \mathrm{~g}$. However, the positive predictive value (PPV) of these variables ranged from 50 to $55 \%$ [14]. A subsequent study from the same center reported a much higher PPV with severe RDS on initial chest radiograph (0.81), but the model lacked sensitivity (32\%) [16]. De Jaegere et al reported that combination of male gender, birth weight $<800 \mathrm{~g}$ and fraction inspired oxygen $\left(\mathrm{FiO}_{2}\right)$ threshold of $\geq 0.25$ at 1 and $2 \mathrm{~h}$ of life (HOL) were predictive of CPAP failure in infants born $<30$ weeks' GA [17]. A two-center prospective study by Dargaville et al suggested that a maximum $\mathrm{FiO}_{2} \geq 0.3$ at 2 HOL predicted CPAP failure in 25-28 week GA infants [11]. Although, the model based on $\mathrm{FiO}_{2}$ is attractive for clinicians, inconstancies between studies raises questions 
about the generalizability of such a threshold. In addition, despite several studies evaluating early predictors of CPAP failure, none of the proposed prediction models have been validated [18].

The objective of our study is to first establish early predictors of CPAP failure using a modeling cohort (MC) to identify a population of infants at risk of requiring intubation within $72 \mathrm{HOL}$, and then to validate the model using a separate validation cohort (VC) of infants with similar demographics.

\section{Methods}

\section{Setting}

Parkland Hospital and Health System (PHHS) is a large public hospital with over 13,000 deliveries annually with a dedicated resuscitation team that attends high risk deliveries. All infants born $\leq 32$ weeks' GA that demonstrate respiratory distress are immediately started on CPAP using a T-Piece resuscitator (Neopuff, ${ }^{\mathrm{TM}}$ Fisher \& Paykel, Auckland, NZ). Face mask positive pressure ventilation (Fm-PPV) is provided when indicated per Neonatal Resuscitation Program (NRP) guidelines. Resuscitation is started at $0.21 \mathrm{FiO}_{2}$ and titrated to meet NRP goal saturation parameters. Peak inspiratory pressure (PIP) is usually set at $25 \mathrm{~cm} \mathrm{H}_{2} \mathrm{O}$ and positive end expiratory pressure (PEEP) at $5 \mathrm{~cm} \mathrm{H}_{2} \mathrm{O}$. Infants stabilized on face mask CPAP are then started on bi-nasal prongs (Hudson Prongs, Hudson RCI, Morrisville, NC) connected to a PEEP valve, running 8-10 $1 \mathrm{~min}^{-1}$ flow before transport to the NICU. Resuscitation details are verbalized by the team members and entered in a paper form in real time by a trained obstetric nurse. A peripheral arterial blood gas (ABG) is obtained upon admission (usually from the right radial artery), a chest radiograph is obtained upon admission or soon after placing the umbilical catheters. Hudson prongs are used exclusively as the nasal interface. Starting May 2014, the CPAP generator was changed from a ventilator to a bubble device. (Fisher \& Paykel Healthcare, Auckland, NZ). Regular training of nurses and respiratory therapists together with bedside auditing of the CPAP delivery system based on previously published guidelines [19] were conducted throughout the study period. There was no set algorithm for escalation of CPAP level and clinical decisions were left to the individual treatment teams. Infants were intubated in the NICU for surfactant therapy if they required $0.45-0.5 \mathrm{FiO}_{2}$ at CPAP level of 5-7 $\mathrm{cm} \mathrm{H}_{2} \mathrm{O}$ or for frequent apnea. The pulse oximeter oxygen saturation target limits in the PHHS NICU are maintained between 88 and $94 \%$. All infants admitted on CPAP are started on ampicillin and gentamicin after initiation of an evaluation for the presence of sepsis and antibiotics are stopped at $48 \mathrm{~h}$ if the blood cultures are negative.

The antenatal steroid (ANS) administration policy was changed in September 2015 from the previous practice of excluding women with pregnancy-induced hypertension (PIH) and diabetes mellitus to now include all mothers with an impending preterm delivery between 24 and 34 week GA [20, 21]. All mothers at risk of preterm delivery $<28$ weeks' GA received magnesium sulfate $\left(\mathrm{MgSO}_{4}\right)$ for neonatal neuroprotection [22].

\section{Study population}

All preterm infants 23-29 weeks' GA admitted to NICU on CPAP between January 2013 and April 2018 were included in the study. Infants intubated in the DR and those receiving only comfort care measures were excluded. Infants were randomly assigned to either the MC or the VC using a random number generator with a 2:1 ratio.

\section{Ethical consideration}

The study was approved by the Institutional Review Board of University of Texas Southwestern Medical Center with waiver of consent for retrospective data collection.

\section{Data collection}

Details of DR resuscitation such as the need for Fm-PPV, intubation, maximum $\mathrm{FiO}_{2}$, Apgar scores, umbilical cord blood gas values, CPAP levels, and $\mathrm{FiO}_{2}$ at admission, at one and two HOL, admission blood gas values and the CPAP level at that time, and the $\mathrm{FiO}_{2}$ and blood gas values at the time of CPAP failure were collected retrospectively from the electronic medical record (EMR) by the members of the study team. Outcome measures such as rates of pneumothorax, bronchopulmonary dysplasia (BPD) and intraventricular hemorrhage (IVH) were obtained from the NICU data base. The first chest radiograph was extracted without patient identifiers and a unique identifier code was applied prior to being assigned to a blinded radiologist to evaluate.

\section{Study outcomes}

Maternal details and neonatal characteristics were compared between the CFG and CSG in both the MC and VC. CPAP failure was defined as the need for intubation within $72 \mathrm{~h}$ of life. Administration of a single dose of betamethasone two hours prior to delivery was considered as exposure to ANS. Maximum $\mathrm{FiO}_{2}$ was calculated from the recorded $\mathrm{FiO}_{2}$ at 1 and $2 \mathrm{HOL}$. The respiratory severity score $=(\mathrm{CPAP}$ level $\times$ $\left.\mathrm{FiO}_{2}\right), \mathrm{A}-\mathrm{a} \mathrm{DO}_{2}=\left[\left(\mathrm{FiO}_{2} \times 713\right)-\left(\mathrm{PaCO}_{2} / 0.8\right)-\mathrm{PaO}_{2}\right]$ and 
arterial/alveolar $\mathrm{PO}_{2}\left(\mathrm{a} / \mathrm{A} \quad \mathrm{PO}_{2}\right)=\left(\mathrm{PaO}_{2} /\left[\left(\mathrm{FiO}_{2} \times 713\right)-\right.\right.$ $\left.\left.\left(\mathrm{PaCO}_{2} / 0.8\right)\right]\right)$ were calculated. A radiologist who was blinded to all clinical information and study design evaluated the first chest radiograph obtained upon admission for lung volume, granularity of the lung parenchyma, degree of atelectasis, visibility of air-bronchograms, presence of interstitial emphysema, and silhouetting of heart borders. The radiologic diagnosis of severe RDS was made in the presence of low lung volumes, diffuse reticular granular pattern and prominent peripheral air bronchograms or with low lung volumes, diffuse opacification of the lungs and indistinct cardiac borders [23]. BPD was defined as the need for supplemental oxygen at 36 weeks' postmenstrual age [24]. Severe IVH was defined as grade III or greater on any ultrasound scans of the head unilaterally or bilaterally as per Papile criteria [25]. Severe ROP was defined as Stage 3 or greater based on the international classification of ROP [26].

\section{Statistical analysis}

Analysis was performed using SPSS version 19 (IBM). Categorical variables were analyzed by Chi square or Fisher's exact test as applicable. Continuous variables were analyzed by Student's $T$-test or Mann-Whitney $U$-test. The level of statistical significance (alpha) for all univariate tests was 0.05 . Any significant missing data $(\geq 5 \%)$ were reported separately.

\section{Creation of the prediction model}

All univariate variables with $P$ value $<0.1$ were included in the multivariate forward stepwise logistic regression analysis. Correlation analysis was conducted to identify any collinearity of these variables. If two variables had high collinearity (Pearson $r \geq 0.6$ ), one of them was removed. Categorical variables used Phi and Cramer's V to evaluate the strength of association between variables. Continuous variables were dichotomized using receiver operating curve at the point of intersection of maximum sensitivity and specificity. The forward stepwise multivariate logistic model allowed only statistically significant variables into the model.

\section{Results}

Of the 529 infants who were actively resuscitated, 284 infants $(54 \%)$ were admitted to the NICU on CPAP. 189 infants $(66 \%)$ were assigned to MC and $95(34 \%)$ to VC. Infants in both these cohorts were further grouped as CSG or CFG. (Fig. 1). Among the entire cohort, nine infants (3\%) were intubated within two HOL and 15 infants $(5 \%)$ did not have $\mathrm{ABG}$ on admission.

\section{Modeling cohort}

Table 1 describes the MC. Of the 189 infants in this cohort, 95 were in the CSG and 94 in the CFG. There were no differences in maternal age and ethnicity. The proportion of mothers receiving ANS was lower among CFG compared to CSG. Mothers in the CFG had a higher proportion of PIH, exposure to intrapartum $\mathrm{MgSO}_{4}$ and Cesarean section. Infants in the CFG also had lower median birth weight

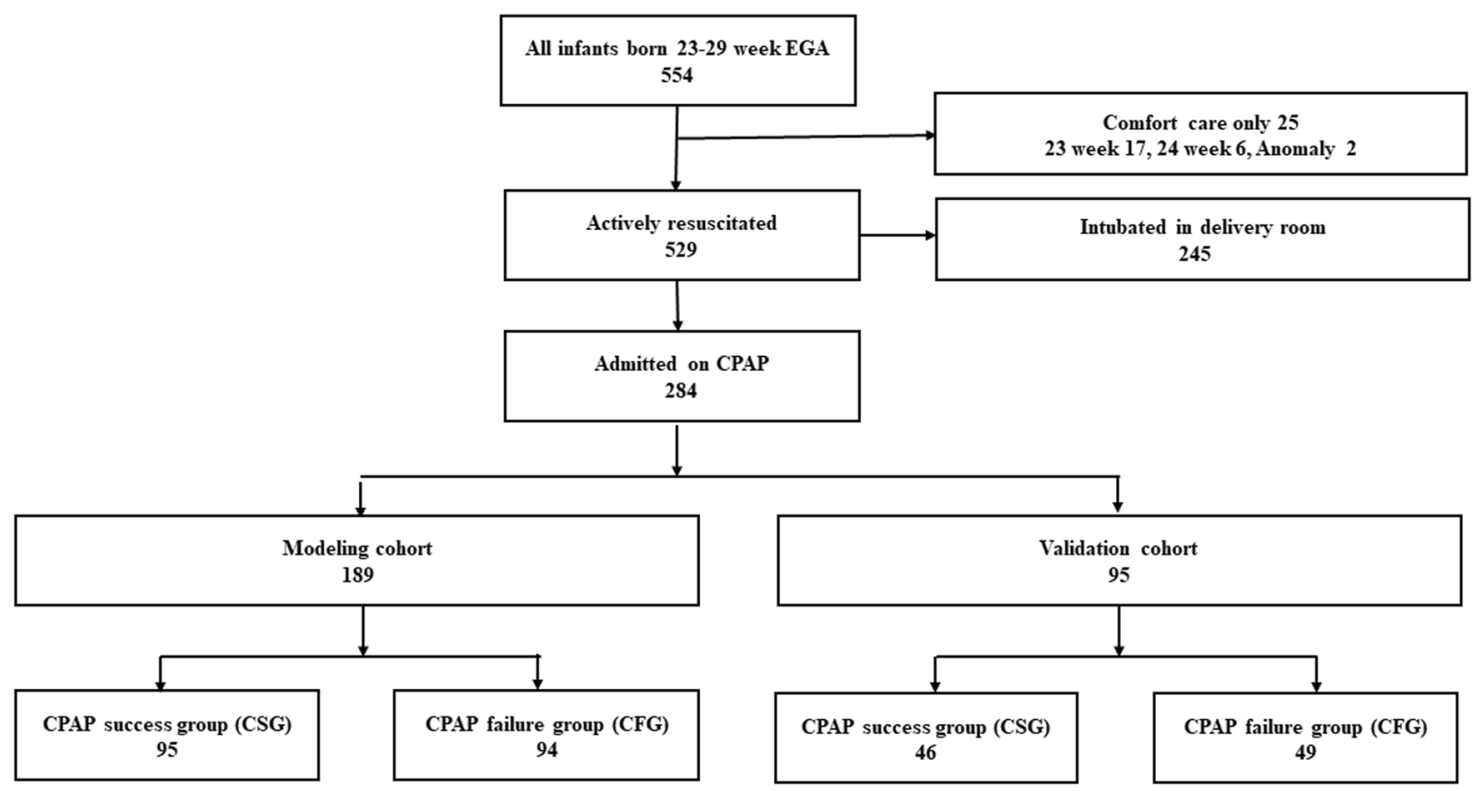

Fig. 1 Flow diagram of study population showing number of infants included in CPAP success group (CSG) and CPAP failure group (CFG) in both modeling cohort (MC) and validation cohort (VC) 
Table 1 Comparison between CPAP success group (CSG) and CPAP failure group (CFG) in the modeling cohort (MC)

\begin{tabular}{|c|c|c|c|}
\hline & $\operatorname{CSG}(n=95)$ & $\mathrm{CFG}(n=94)$ & $P$-value \\
\hline Maternal age, $\left(\right.$ year) ${ }^{\mathrm{a}}$ & $27(21,34)$ & $30(23,35)$ & NS \\
\hline Hispanic $n(\%)$ & $72(76)$ & $64(68)$ & NS \\
\hline $\mathrm{PIH} n$ & $22(24)$ & $49(54)$ & $<0.01$ \\
\hline ANS $n(\%)$ & $77(83)$ & $61(67)$ & 0.01 \\
\hline Antenatal $\mathrm{MgSO}_{4} n(\%)$ & $54(58)$ & $66(73)$ & 0.04 \\
\hline Cesarean section $n(\%)$ & $57(60)$ & $74(79)$ & $<0.01$ \\
\hline Male $n(\%)$ & $42(44)$ & $54(58)$ & 0.06 \\
\hline $\mathrm{GA}(\text { weeks })^{\mathrm{a}}$ & $28(27,29)$ & $27(26,29)$ & 0.09 \\
\hline Birth weight $(\mathrm{g})^{\mathrm{a}}$ & $\begin{array}{l}1145 \\
(938,1355)\end{array}$ & $1010(850,1285)$ & 0.03 \\
\hline Fm-PPV in DR $n(\%)^{\mathrm{a}}$ & $57(60)$ & $61(65)$ & NS \\
\hline $\begin{array}{l}\text { Umbilical cord blood } \\
\text { gas } \mathrm{pH}^{\mathrm{a}}\end{array}$ & $\begin{array}{l}7.28 \\
(7.24,7.32)\end{array}$ & $7.27(7.24,7.30)$ & NS \\
\hline $\begin{array}{l}\text { Maximum } \mathrm{FiO}_{2} \\
\text { within } 2 \mathrm{~h}\end{array}$ & $25(21,30)$ & $35(29,46)$ & $<0.01$ \\
\hline $\begin{array}{l}\text { CPAP level at } 2 \mathrm{HOL} \\
\left(\mathrm{cm} \mathrm{H}_{2} \mathrm{O}\right)^{\mathrm{a}}\end{array}$ & $5(5,6)$ & $5(5,6)$ & NS \\
\hline $\mathrm{A}-\mathrm{a} \mathrm{DO}_{2}{ }^{\mathrm{a}}$ & $75(32.0,91)$ & $126(81,169)$ & $<0.01$ \\
\hline $\mathrm{a} / \mathrm{A} \mathrm{PO}_{2}{ }^{\mathrm{a}}$ & $\begin{array}{l}0.40 \\
(0.30,0.47)\end{array}$ & $0.24(0.20,0.33)$ & $<0.01$ \\
\hline $\begin{array}{l}\text { Radiographic severe } \\
\text { RDS } n(\%)\end{array}$ & $5(5)$ & $21(22)$ & $<0.01$ \\
\hline Pneumothorax $n(\%)$ & $4(4)$ & $9(10)$ & NS \\
\hline BPD $n(\%)$ & $4(4)$ & $16(17)$ & $<0.01$ \\
\hline Severe IVH $n(\%)$ & $1(1)$ & $3(3)$ & NS \\
\hline Severe ROP $n(\%)$ & $2(2)$ & $8(9)$ & 0.06 \\
\hline Mortality $n(\%)$ & $3(3)$ & $9(10)$ & 0.07 \\
\hline
\end{tabular}

NS not significant

${ }^{a}$ Median (25th, 75th)

compared to CSG. In addition, median maximum $\mathrm{FiO}_{2}$ within two $\mathrm{HOL}$ and $\mathrm{A}-\mathrm{a} \mathrm{DO}_{2}$ were higher and median a/A $\mathrm{PO}_{2}$ was lower in the CFG compared to CSG. A higher proportion of infants had severe RDS on first chest radiograph in the CFG. The CFG also had higher incidence of BPD ( $4 \%$ vs. $17 \% P \leq 0.01)$ compared to CSG.

Among infants who failed CPAP in the MC, the median time for CPAP failure was $5.9 \mathrm{~h}$ in the entire cohort. There were no differences between the 23-26 weeks' and 27-29 weeks' GA categories in the time to CPAP failure, median $\mathrm{FiO}_{2}$, CPAP level, A-a $\mathrm{DO}_{2}$, a/A $\mathrm{PO}_{2}$, and $\mathrm{PaCO}_{2}$ (Table 2).

The proportion of infants with $\mathrm{PIH}$ and exposure to magnesium sulfate were collinear with Cesarean section. Similarly, median $\mathrm{PaO}_{2}, \mathrm{~A}-\mathrm{a} \mathrm{DO}_{2}$, and birth weight were collinear with median maximum $\mathrm{FiO}_{2}$ within two $\mathrm{HOL}$, a/A $\mathrm{PO}_{2}$ and $\mathrm{GA}$, respectively. Continuous variables were dichotomized at maximum $\mathrm{FiO}_{2}>0.3$ within two $\mathrm{HOL}$ (sensitivity: 0.75 , specificity: 0.68 , PPV 0.71 ) and a/A
$\mathrm{PO}_{2} \leq 0.22$ (sensitivity: 0.39, specificity: 0.93, and PPV 0.66).

The forward stepwise logistic regression model showed that combination of three factors including maximum $\mathrm{FiO}_{2}$ $>0.3$ within two HOL, radiographic severe RDS by first $\mathrm{CXR}$, and a/ $\mathrm{A}_{2} \leq 0.22$ predicted CPAP failure, with the area under the receiver operator curve (AUC) of 0.78 (Table 3).

\section{Validation cohort}

Table 4 describes the VC. Of the 95 infants in the VC, 46 were in the CSG and 49 were in the CFG. There were no differences between two groups with maternal age, ethnicity, exposure to ANS and Cesarean section rate. However, mothers in the CFG had significantly higher proportion of PIH rate compared to CSG. In addition, compared to CSG, infants in the CFG had lower median birth weight and a/A $\mathrm{PO}_{2}$, higher median maximum $\mathrm{FiO}_{2}$ within two HOL and higher proportion of radiographic severe RDS.

Forward stepwise logistic regression of the VC confirmed maximum $\mathrm{FiO}_{2}$ within two $\mathrm{HOL}$ and radiographic severe RDS as the two most important predictors of CPAP

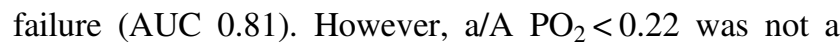
significant predictor of CPAP failure in the VC (Table 3).

\section{Discussion}

Our single center study shows that combination of maximum $\mathrm{FiO}_{2}>0.3$ within two HOL and severe RDS on initial chest radiograph are the most important predictors of CPAP failure among infants born $\leq 29$ weeks' GA. To the best of our knowledge, this is the first study to establish a validated prediction model for CPAP failure.

Our study differs from previous reports by Dargaville et al. where a maximum $\mathrm{FiO}_{2} \geq 0.3$ within two $\mathrm{HOL}$ was the single most important predictor of CPAP failure [11] and the study by Tagleafero et al., where severe RDS on initial chest radiograph predicted CPAP failure [16]. In our study, although $\mathrm{FiO}_{2}$ was the primary driver of our predictive model in both cohorts, severe RDS on first radiograph was a significant predictor, adding further strength to the model. The differences between the previous studies and our study could be attributed primarily to the study design. Tagliafero et al. did not evaluate the predictive value of $\mathrm{FiO}_{2}$ in the first few hours of life and Dargaville et al. did not evaluate the severity of RDS in the first radiograph.

The success rates of CPAP vary between centers [27]. Several factors may contribute to the success of CPAP therapy in an individual unit [28]. Role of higher versus lower $\mathrm{FiO}_{2}$ thresholds and CPAP level on the success of CPAP therapy is not clear. De Jaeger et al proposed a 
Table 2 Respiratory status at the time of CPAP failure in the modeling cohort (MC)

\begin{tabular}{|c|c|c|c|}
\hline Characteristic & $\begin{array}{l}\text { All infants (A) } \\
(n=94)\end{array}$ & $\begin{array}{l}23-26 \text { week GA (B) } \\
(n=32)\end{array}$ & $\begin{array}{l}27-29 \text { week GA }(C) \\
(n=62)\end{array}$ \\
\hline Time to failure $(\mathrm{h})^{\mathrm{a}}$ & $5.9(2.3,18.1)$ & $4.9(1.6,17.5)$ & $6.4(2.8,20.7)$ \\
\hline $\mathrm{FiO}_{2}{ }^{\mathrm{a}}$ & $0.49(40,54)$ & $0.50(0.43,0.60)$ & $0.48(0.40,0.50)$ \\
\hline CPAP level $\left(\mathrm{cm} \mathrm{H}_{2} 0\right)^{\mathrm{a}}$ & $6(5,6)$ & $6(6,6)$ & $6(5,6)$ \\
\hline A-a gradient $\mathrm{t}^{\mathrm{a}}$ & $260(204,305)$ & $265(217,355)$ & $255(204,289)$ \\
\hline $\mathrm{a} / \mathrm{A} \mathrm{PO}_{2}{ }^{\mathrm{a}}$ & $0.14(0.11,0.18)$ & $0.13(0.10,0.17)$ & $0.14(0.11,0.19)$ \\
\hline $\mathrm{PaCO}_{2} \mathrm{~mm} \mathrm{Hg}^{\mathrm{a}}$ & $48(43,57)$ & $50(45,58)$ & $48(43,56)$ \\
\hline
\end{tabular}

${ }^{\mathrm{a}}$ Median (25th, 75th)
Table 3 Forward step multivariate stepwise logistic regression model for CPAP failure in both modeling cohort and validation cohort

\begin{tabular}{lcr}
\hline & Odds ratio $(95 \% \mathrm{CI})$ & $P$-value \\
\hline Modeling cohort & $3.27(1.04,10.28)$ & 0.04 \\
Radiographic severe RDS & $3.89(1.85,8.17)$ & $<0.01$ \\
Maximum $\mathrm{FiO}_{2}>0.30$ & $4.17(1.51,11.54)$ & $<0.01$ \\
a/A $\mathrm{PO}_{2} \leq 0.22$ & & \\
Validation cohort & $21.54(2.32,199.91)$ & $<0.01$ \\
Radiographic severe RDS & $6.69(2.13,21.00)$ & $<0.01$ \\
${\text { Maximum } \mathrm{FiO}_{2}>0.30}_{\text {a/A } \mathrm{PO}_{2} \leq 0.22}$ & $1.62(0.26,9.94)$ & $\mathrm{NS}$ \\
\hline
\end{tabular}

predictive model including male gender, birth weight $<800$ $\mathrm{g}$ and $\mathrm{FiO}_{2} \geq 0.25$ at 1 and $2 \mathrm{HOL}$ for infants born $<30$ weeks' GA from a center that intubated infants at 0.4 $\mathrm{FiO}_{2}$ at CPAP level $7 \mathrm{~cm} \mathrm{H}_{2} \mathrm{O}$ [17]. The Dargaville et al. study used the $\mathrm{FiO}_{2}$ threshold of 0.5 at CPAP level of $8 \mathrm{~cm}$ $\mathrm{H}_{2} \mathrm{O}$. Our center used CPAP level of 5-7 at $\mathrm{FiO}_{2}$ of $0.45-0.5$. The average time to failure in our study is comparable to Dargaville et al. study, although the median $\mathrm{FiO}_{2}$ at the time of intubation was lower (0.4 vs. 0.5) [11]. However, the CPAP failure rates were similar in these studies (40-45\%). Interestingly, Fuchs et al. showed that targeting $0.35-0.45 \mathrm{FiO}_{2}$ can decrease the time to intubation without significantly increasing the risk of unnecessary intubation compared to a threshold of $0.6 \mathrm{FiO}_{2}$ at CPAP level of $8 \mathrm{~cm} \mathrm{H}_{2} 0$ [13]. This could explain the similar CPAP failure rates between studies, despite differences in the thresholds used. Our proposed model incorporates the $\mathrm{FiO}_{2}$ thresholds suggested by Dargaville et al. and the radiographic model suggested by Tagleaferro et al. and therefore will mitigate the bias introduced by center differences in $\mathrm{FiO}_{2}$ thresholds and improve the sensitivity of the prediction model. The level of CPAP did not provide additional strength to the predictive model than when $\mathrm{FiO}_{2}>0.3$ was used by itself. This is in concordance with the findings of Dargaville et al. [11].

Identifying the group of infants that will fail CPAP by two HOL is important to target interventions to decrease CPAP failure. Increasing the CPAP level improves
Table 4 Comparison between CPAP success group (CSG) and CPAP failure group (CFG) in the validation cohort (VC)

\begin{tabular}{|c|c|c|c|}
\hline Characteristics & $\operatorname{CSG}(n=46)$ & CFG $(n=49)$ & $P$-value \\
\hline Maternal age (year) ${ }^{\mathrm{a}}$ & $29(24,33)$ & $29(23,33)$ & NS \\
\hline Hispanic $n(\%)$ & $30(65)$ & $28(57)$ & NS \\
\hline $\mathrm{PIH} n(\%)$ & $11(24)$ & $25(54)$ & $<0.01$ \\
\hline ANS $n(\%)$ & $38(83)$ & $33(72)$ & NS \\
\hline $\begin{array}{l}\text { Antenatal } \mathrm{MgSO}_{4} n \\
(\%)\end{array}$ & $22(48)$ & $34(74)$ & 0.01 \\
\hline Cesarean section $n(\%)$ & $31(67)$ & $39(81)$ & NS \\
\hline Male $n(\%)$ & $16(35)$ & $21(43)$ & NS \\
\hline $\mathrm{GA}(\text { weeks })^{\mathrm{a}}$ & $28(27,29)$ & $27(26,29)$ & 0.06 \\
\hline Birth weight $(\mathrm{g})^{\mathrm{a}}$ & $1105(944,1410)$ & $950(835,1170)$ & 0.02 \\
\hline $\begin{array}{l}\text { Face mask PPV in DR, } \\
n(\%)\end{array}$ & $30(65)$ & $35(71)$ & NS \\
\hline $\begin{array}{l}\text { Umbilical cord } \\
\text { blood gas PH }\end{array}$ & $7.28(7.24,7.32)$ & $7.26(7.21,7.31)$ & NS \\
\hline $\begin{array}{l}\mathrm{Max} \mathrm{FiO}_{2} \\
\text { within } 2 \mathrm{HOL}\end{array}$ & $0.23(0.21,0.30)$ & $0.37(0.30,0.45)$ & $<0.01$ \\
\hline $\begin{array}{l}\text { CPAP level at } 2 \mathrm{HOL} \\
\left(\mathrm{cm} \mathrm{H}_{2} \mathrm{O}\right)^{\mathrm{a}}\end{array}$ & $5(5,6)$ & $5(5,6)$ & NS \\
\hline $\mathrm{A}-\mathrm{a} \mathrm{DO}_{2}^{\mathrm{a}}$ & $63(22,92)$ & $120(52,175)$ & $<0.01$ \\
\hline $\mathrm{a} / \mathrm{APO}_{2}^{\mathrm{a}}$ & $0.40(0.31,0.5)$ & $0.28(0.21,0.37)$ & $<0.01$ \\
\hline $\begin{array}{l}\text { Radiographic severe } \\
\text { RDS } n(\%)\end{array}$ & $1(2)$ & $15(32)$ & $<0.01$ \\
\hline
\end{tabular}

NS not significant

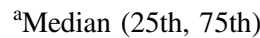

functional residual capacity [29], decreases work of breathing [30], decreases intrapulmonary shunting and ventilation perfusion mismatch in the setting of RDS and thus decrease oxygen requirement [31]. There are concerns raised about the risk of pneumothorax by delaying surfactant administration with higher CPAP levels [9], but large studies using levels upto $7 \mathrm{~cm} \mathrm{H}_{2} \mathrm{O}$ show no increase in air leak [10]. In addition to the higher $\mathrm{FiO}_{2}$ thresholds used for intubation, a single center experience of higher success rate than all other centers may be related to additional factors such as better positioning, use of a chin strap, appropriate prong size, airway clearance, frequent monitoring and buy in from the multidisciplinary team [28]. In order to 
minimize exposure to MV, prophylactic rescue surfactant therapy using an Intubation SURfactant and rapid Extubation (INSURE) strategy was studied [32-34]. This strategy did not decrease the need for MV compared to early CPAP and rescue surfactant [35]. Early rescue INSURE using a lower $\mathrm{FiO}_{2}$ threshold has been suggested as an alternative to rescue INSURE or rescue surfactant and continued MV for infants at risk for CPAP failure [36]. The Less Invasive Surfactant Administration (LISA) strategy of tracheal instillation of surfactant using a thin catheter while continuing CPAP decreases the need for MV [37-39]. Two randomized control trials (RCT) used a threshold $\mathrm{FiO}_{2}$ of 0.3 at CPAP level of $4-6 \mathrm{~cm} \mathrm{H}_{2} \mathrm{O}[37,38,40]$. A single RCT evaluated LISA with INSURE at $\mathrm{FiO}_{2} 0.4$ at CPAP level of $5-7 \mathrm{~cm} \mathrm{H}_{2} \mathrm{O}$ [39]. Currently, a large RCT is underway comparing LISA with rescue surfactant and MV using a threshold of $\mathrm{FiO}_{2}>0.3$ with CPAP level $\geq 7 \mathrm{~cm} \mathrm{H}_{2} \mathrm{O}$ [41]. Further, a recent survey conducted in the United States indicates that the use of LISA is currently very limited [42].

Our study has several strengths. First, this is the first study to validate the predictive model using a separate VC. Infants were randomly assigned to each cohort to minimize the affect of any temporal changes in practice. In addition, a large number of variables that are routinely available during first few hours of life were evaluated for inclusion in the prediction model. Second, the predictors of CPAP failure in our study although different, is in alignment with the previous models that suggested $\mathrm{FiO}_{2}$ and severity of RDS by radiograph as the most important predictors [11]. A lower $\mathrm{FiO}_{2}$ threshold and level of CPAP were used for intubation for surfactant therapy in our cohort compared to the two previous studies evaluating predictors of CPAP failure provided the opportunity to test the proposed model in a different setting. Third, 95\% of infants in the study cohort had an ABG upon admission to NICU. This provided a unique opportunity to evaluate the utility of a/ $\mathrm{A} \mathrm{PO}_{2}$ and Aa $\mathrm{DO}_{2}$ as a predictor of CPAP failure. A previous study by Ammari et al. suggested that an A-a $\mathrm{DO}_{2}$ of 180 and severe RDS on initial chest radiograph are predictors of CPAP failure $[14,43]$. In our study, A-a $\mathrm{DO}_{2}$ was highly collinear with $\mathrm{FiO}_{2}$ therefore was not included in the model. This confirms the observation from previous studies which showed that $\mathrm{SpO}_{2}$ is highly correlated with $\mathrm{PaO}_{2}$ in preterm neonates with acute and chronic lung disease [33]. Lastly, the initial chest radiograph was read by a single radiographer who was blinded to patient information and study design. This study design decreases the possibility of bias.

There are several limitations to this study. First, the ANS rate in our study population is lower compared to previous reports. The noted lower ANS rate among CFG compared to CSG in the MC in our study could be explained by the lower ANS in our cohort. However, ANS exposure did not add further strength to the predictive model in either cohort. Second, although the threshold for intubation and surfactant is generally uniform in our unit, variations in practice exist between treating teams. This limitation was also noted in other similar studies [16]. Third, although by protocol ABGs were drawn from right radial artery (pre-ductal), in some situations, the ABG may have been drawn from the left radial or from umbilical arterial lines. This may affect the a/A $\mathrm{PO}_{2}$ and A-a $\mathrm{DO}_{2}$ values. Fourth, 23-24 weeks GA infants accounted for only $5 \%$ of the entire cohort. Therefore, caution should be exercised when using these thresholds for infants at the edge of viability. Further studies in this small group of neonates are required to define the right strategy. Lastly, all radiographs were read by a single pediatric radiologist and inter rater reliability of the evaluation of chest radiographs between radiologist and neonatologists has not been tested. However, identification of severe RDS on radiographs is routinely done on standards widely described in the literature and less likely to be subjective compared to radiographic mild or moderate RDS [44].

In conclusion, this retrospective study shows that a $\mathrm{FiO}_{2}$ $>0.30$ within two HOL and severe RDS on first chest radiograph predicts CPAP failure in the group of neonates born $<30$ weeks' GA. This threshold needs to be further evaluated in multicenter study involving larger cohort of infants cared for in different settings. Such threshold can help target early interventions to decrease exposure to mechanical ventilation.

Acknowledgements We thank Patti Jeannette Burchfield, RN for her work in collecting and extracting data for the NICU database. The Journal Club is a collaboration between the American Academy of Pediatrics - Section of Neonatal Perinatal Medicine and the International Society for Evidence-Based Neonatology (EBNEO.org).

Funding VSK acknowledges support by K23HD083511 grant by NIH. RCS holds the William Buchanan Chair in Pediatrics at UT Southwestern Medical Center.

Author contributions Dr. Venkatakrishna Kakkilaya conceptualized and designed the study, wrote all drafts of the manuscript, assisted with data analysis and interpretation. Ms. Sheron Wagner, Dr. Ihab Jubran, Mr. Henry He, participated in the study design, data collection and reviewed the manuscript. Mr. Larry Steven Brown participated in the study design, conducted the analysis of the data, reviewed and revised the manuscript. Dr. Rashmin Savani participated in the design of the study, interpretation of data, reviewed and revised the manuscript. Dr. Vishal Kapadia: conceptualized and designed the study, participated in interpretation of data, reviewed and revised the manuscript.

\section{Compliance with ethical standards}

Conflict of interest The authors declare that they have no conflict of interest. 
Publisher's note: Springer Nature remains neutral with regard to jurisdictional claims in published maps and institutional affiliations.

\section{References}

1. Hillman NH, Kallapur SG, Pillow JJ, et al. Airway injury from initiating ventilation in preterm sheep. Pediatr Res. 2010;67:60-65.

2. Hillman NH, Moss TJ, Kallapur SG, et al. Brief, large tidal volume ventilation initiates lung injury and a systemic response in fetal sheep. Am J Respir Crit Care Med. 2007;176:575-81.

3. Bjorklund LJ, Ingimarsson $\mathrm{J}$, Curstedt $\mathrm{T}$, et al. Manual ventilation with a few large breaths at birth compromises the therapeutic effect of subsequent surfactant replacement in immature lambs. Pediatr Res. 1997;42:348-55.

4. Rojas-Reyes MX, Morley CJ, Soll R. Prophylactic versus selective use of surfactant in preventing morbidity and mortality in preterm infants. Cochrane Database Syst Rev. 2012;3:CD000510.

5. Schmolzer GM, Kumar M, Pichler G, Aziz K, O'Reilly M, Cheung PY. Non-invasive versus invasive respiratory support in preterm infants at birth: systematic review and meta-analysis. BMJ. 2013;347:f5980.

6. Subramaniam P, Ho JJ, Davis PG. Prophylactic nasal continuous positive airway pressure for preventing morbidity and mortality in very preterm infants. Cochrane Database Syst Rev. 2016;6: Cd001243.

7. Stoll BJ, Hansen NI, Bell EF, et al. Trends in care practices, morbidity, and mortality of extremely preterm neonates, 1993-2012. Jama. 2015;314:1039-51.

8. Kakkilaya V, Jubran I, Mashruwala V, et al. Quality improvement project to decrease delivery room intubations in preterm infants. Pediatrics. 2019;143:e20180201.

9. Morley CJ, Davis PG, Doyle LW, Brion LP, Hascoet JM, Carlin JB. Nasal CPAP or intubation at birth for very preterm infants. N Engl J Med. 2008;358:700-8.

10. Network SSGotEKSNNR, Finer NN, Carlo WA, et al. Early $\mathrm{CPAP}$ versus surfactant in extremely preterm infants. $\mathrm{N}$ Engl $\mathrm{J}$ Med. 2010;362:1970-9.

11. Dargaville PA, Aiyappan A, De Paoli AG, et al. Continuous positive airway pressure failure in preterm infants: incidence, predictors and consequences. Neonatology. 2013;104:8-14.

12. Dargaville PA, Gerber A, Johansson S, et al. Incidence and outcome of CPAP failure in preterm infants. Pediatrics. 2016;138: e20153985.

13. Fuchs H, Lindner W, Leiprecht A, Mendler MR, Hummler HD. Predictors of early nasal CPAP failure and effects of various intubation criteria on the rate of mechanical ventilation in preterm infants of $<29$ weeks gestational age. Arch Dis Child Fetal Neonatal Ed. 2011;96:F343-347.

14. Ammari A, Suri M, Milisavljevic V, et al. Variables associated with the early failure of nasal CPAP in very low birth weight infants. J Pediatr. 2005;147:341-7.

15. Pillai MS, Sankar MJ, Mani K, Agarwal R, Paul VK, Deorari AK. Clinical prediction score for nasal CPAP failure in pre-term VLBW neonates with early onset respiratory distress. J Trop Pediatr. 2011;57:274-9.

16. Tagliaferro T, Bateman D, Ruzal-Shapiro C, Polin RA. Early radiologic evidence of severe respiratory distress syndrome as a predictor of nasal continuous positive airway pressure failure in extremely low birth weight newborns. J Perinatol. 2014;35:99.

17. De Jaegere AP, van der Lee JH, Cante C, van Kaam AH. Early prediction of nasal continuous positive airway pressure failure in preterm infants less than 30 weeks gestation. Acta Paediatr. 2012;101:374-9.
18. Altman DG, Royston P. What do we mean by validating a prognostic model? Stat Med. 2000;19:453-73.

19. Bonner KM, Mainous RO. The nursing care of the infant receiving bubble CPAP therapy. Adv Neonatal Care. 2008;8:78-95.

20. Bloom SL, Leveno KJ. Corticosteroid use in special circumstances: preterm ruptured membranes, hypertension, fetal growth restriction, multiple fetuses. Clin Obstet. Gynecol. 2003;46:150-60.

21. ACOG Committee Opinion. Antenatal corticosteroid therapy for fetal maturation. American College of Obstetricians and Gynecologists. Int J Gynaecol Obstet. 2002;78:95-97.

22. Committee Opinion No. 455: Magnesium sulfate before anticipated preterm birth for neuroprotection. Obstet Gynecol. 2010;115:669-71.

23. Sivit CJ. Diagnostic imaging. In: Martin RJ, Fanaroff, AA, Walsh, MC, editors. Fanaroff and Martin's neonatal-perinatal medicine: diseases of the fetus and infant. Vol 1. 8th ed. Maryland Heights: Mosby Elsevier; 2005. p. 713-4.

24. Walsh MC, Szefler S, Davis J, et al. Summary proceedings from the bronchopulmonary dysplasia group. Pediatrics. 2006;117: S52-56.

25. Papile LA, Burstein J, Burstein R, Koffler H. Incidence and evolution of subependymal and intraventricular hemorrhage: a study of infants with birth weights less than 1500 g. J Pediatr. 1978;92:529-34.

26. International Committee for the Classification of Retinopathy of Prematurity. The International Classification of Retinopathy of Prematurity revisited. Arch Ophthalmol. 2005;123:991-9.

27. Wright CJ, Sherlock LG, Sahni R, Polin RA. Preventing continuous positive airway pressure failure: evidence-based and physiologically sound practices from delivery room to the neonatal intensive care unit. Clin Perinatol. 2018;45:257-71.

28. Sahni R, Schiaratura M, Polin RA. Strategies for the prevention of continuous positive airway pressure failure. Semin Fetal Neonatal Med. 2016;21:196-203.

29. Saunders RA, Milner AD, Hopkin IE. The effects of continuous positive airway pressure on lung mechanics and lung volumes in the neonate. Biol Neonate. 1976;29:178-86.

30. Locke R, Greenspan JS, Shaffer TH, Rubenstein SD, Wolfson MR. Effect of nasal CPAP on thoracoabdominal motion in neonates with respiratory insufficiency. Pedia Pulmonol. 1991;11:259-64.

31. Gregory GA, Kitterman JA, Phibbs RH, Tooley WH, Hamilton WK. Treatment of the idiopathic respiratory-distress syndrome with continuous positive airway pressure. $\mathrm{N}$ Engl $\mathrm{J}$ Med. 1971;284:1333-40.

32. Verder H, Albertsen P, Ebbesen F, et al. Nasal continuous positive airway pressure and early surfactant therapy for respiratory distress syndrome in newborns of less than 30 weeks' gestation. Pediatrics. 1999; 103:E24.

33. Neonatal Drug Withdrawal. American Academy of Pediatrics Committee on Drugs. Pediatrics. 1998;101:1079-88.

34. Dunn MS, Kaempf J, de Klerk A, et al. Randomized trial comparing 3 approaches to the initial respiratory management of preterm neonates. Pediatrics. 2011;128:e1069-1076.

35. Isayama $\mathrm{T}$, Chai-Adisaksopha $\mathrm{C}$, McDonald SD. Noninvasive ventilation with vs without early surfactant to prevent chronic lung disease in preterm infants: a systematic review and meta-analysis. JAMA Pediatr. 2015;169:731-9.

36. Sweet DG, Carnielli V, Greisen G, et al. European Consensus Guidelines on the Management of Respiratory Distress Syndrome -2016 Update. Neonatology. 2017;111:107-25.

37. Göpel W, Kribs A, Ziegler A, et al. Avoidance of mechanical ventilation by surfactant treatment of spontaneously breathing 
preterm infants (AMV): an open-label, randomised, controlled trial. Lancet. 2011;378:1627-34.

38. Kribs A, Roll C, Gopel W, et al. Nonintubated surfactant application vs. conventional therapy in extremely preterm infants: a randomized clinical trial. JAMA Pediatr. 2015;169:723-30.

39. Kanmaz HG, Erdeve O, Canpolat FE, Mutlu B, Dilmen U. Surfactant administration via thin catheter during spontaneous breathing: randomized controlled trial. Pediatrics. 2013;131: e502-9.

40. Bao Y, Zhang G, Wu M, Ma L, Zhu J. A pilot study of less invasive surfactant administration in very preterm infants in a Chinese tertiary center. BMC Pediatr. 2015;15:21.
41. Dargaville PA, Kamlin CO, De Paoli AG, et al. The OPTIMIST-A trial: evaluation of minimally-invasive surfactant therapy in preterm infants 25-28 weeks gestation. BMC Pediatr. 2014;14:213.

42. Kurepa D, Perveen S, Lipener Y, Kakkilaya V. The use of less invasive surfactant administration (LISA) in the United States with review of the literature. J Perinatol. 2019;39:426-32.

43. Wright CJ, Sherlock LG, Sahni R, Polin RA. Preventing continuous positive airway pressure failure. Clin Perinatol. 2018;45:257.

44. Kero PO, Makinen EO. Comparison between clinical and radiological classification of infants with the respiratory distress syndrome (RDS). Eur J Pediatr. 1979;130:271-8. 